correlation appears particularly strong for research with ties to food companies. Marion Nestle, author of Food Politics and the Paulette Goddard Professor in the Department of Nutrition, Food Studies and Public Health at New York University, has been informally tracking studies with connections to the food industry for more than a year. Of the 168 studies she came across between March 2015 and March 2016, only 12 had results unfavourable to a sponsor's interest. In other words, the success rate was $93 \%$.

In an email to CMAJ, Nestle said the dairy industry is funding studies in part because their products are "under siege" by some critics who think "dairy foods are poison." She cited T. Colin Campbell, professor emeritus of nutritional biochemistry at Cornell University, as an example. In articles posted on the website of the T. Colin Campbell Center for Nutrition Studies, Campbell says there are many "frightening facts" about milk, and claims, among other "provocations," that dairy protein causes cancer.

"The US Dairy Council sends me every study that proves the benefits of dairy for health, but not the ones that don't," wrote Nestle. "If the purpose of the studies is to promote dairy foods, the studies are about marketing, not health."

Canada's Dairy Research Cluster, however, defends the integrity of the research it funds. In an email to $C M A J$, Shelley Crabtree, a communications specialist with the cluster, said the research is impartial and unbiased. The studies funded by Dairy Farmers of Canada in nutrition, food science and health are chosen by an independent committee of experts, who must disclose any possible conflicts of interests. If committee members are also applying for funding from Dairy Farmers of Canada, they must leave the room when their proposals are assessed for scientific merit. They are also precluded from discussions about projects associated with their employers (such as a university) or a co-investigator on another project.

The decision to publish findings "rests solely with the researchers," she noted, adding that sources of funding are always disclosed to ensure transparency. "Researchers maintain complete independence in conducting their study, owning their data and reporting the outcomes, regardless of the studies' results," wrote Crabtree. "We are confident that researchers from Canadian universities that receive funding from [Dairy Farmers of Canada] are committed to solid, credible and ethical science that can stand the test of time."

As for Agriculture and Agri-Food Canada, the department "assesses the soundness of a project's research methodology through a scientific peerreview process in which every proposal is reviewed by one or more scientists with an appropriate scientific specialty,"
James Watson, a media relations representative, said in an email to CMAJ. "In order to preclude any conflict of interest, these assessing scientists must not be connected to the project in any way."

One study funded by Dairy Farmers of Canada and conducted by researchers at Brock University is examining the role of dairy products in weight management for teenage girls. In an email to $C M A J$, Andrea Josse, assistant professor of kinesiology and one of the researchers, said there are no conditions attached to the funding. Josse noted that Dairy Farmers of Canada did not design or commission the study, and her team is free to publish the results, however they turn out, in the journal of their choosing.

"I am not 'concerned' that my work may turn into promotional material for the dairy industry. If they can use our data/research in a positive way to encourage more consumption of dairy in populations that don't consume enough (according to Canadian statistics), then that is fine by me," wrote Josse. "We believe in the health benefits of dairy (particularly in adolescents — which is the population we're doing our study in), so if we see good results, we hope they are disseminated accordingly by both [Dairy Farmers of Canada] and Brock University." — Roger Collier, CMAJ

CMAJ 2016. DOI:10.1503/cmaj.109-5278

\title{
Drugs are going missing, but why?
}

$\mathrm{D}$ r. Jacalyn Duffin, a hematologist and medical historian at Queen's University, Kingston, Ontario, first became aware that certain drugs were sometimes getting hard to find in 2010, when her patient at a cancer clinic wanted to stop chemotherapy because she couldn't get prochlorperazine, a common antinausea drug.

Duffin was shocked. "I just couldn't believe that it was gone. It is a very old, reliable drug that has been around for a long time and it was the only one that worked for her."

Duffin started investigating and quickly discovered the problem went far beyond an old antinausea drug. "It's affecting all classes of drugs, as far as we can tell. There are drugs missing for treating mental illness, there are chemotherapy drugs missing in cancer care, there are painkillers missing, there are anti-inflammatory drugs that have gone missing, there are blood pressure drugs that have gone missing, there are antibiotics that have gone missing."

The problem is found in many countries, though the form may differ by jurisdiction. In the United States, for example, a lot more injectables are missing than in Canada, said Duffin.

But more worrying than the missing drugs, she said, is that we don't really know how big the problem is, or what is causing it. "Nobody is measuring it properly," she said. "And without measuring it properly, it is very hard to describe it and to know if it is getting better, or getting worse."

To try to fill that gap, Duffin has been collecting reports of shortages, possible causes and patient stories on her website, www.canadadrugshortage.com.

A possible clue to the cause of the shortages may be in the one thing they mostly have in common: the missing drugs are usually generics. In other words, they are older drugs without patent protection. These drugs are less lucrative than new blockbuster drugs or most drugs still on patent, and com- 
panies must sell huge volumes to turn a profit. This results in a shaky supply chain; often only a few companies manufacture each drug and if it becomes uneconomical, they may stop production.

The Canadian Generic Pharmaceutical Association declined to be interviewed, but Jeff Connell, the association's vice-president of corporate affairs, stated in an email that: "The root causes of drug shortages are complex and are influenced by both domestic and international factors. The most common causes for drug shortages are availability of active ingredients, manufacturing issues, regulatory issues and marketplace issues."

There are some examples of regulatory and manufacturing issues. After some supplies of the blood thinner heparin were found to be contaminated in 2008, government inspectors such as Health Canada and the US Food and Drug Administration (FDA) stepped up inspections of manufacturers and tightened safety rules. This led to disruptions in supply as factories were shut down or retooled to meet the new standards.

Evolving standards at regulatory agencies such as the FDA, Health Canada and the European Medicines Agency, have "led to some production being shut down for periods of time in order for changes to be made to be in compliance," said Connell.

How health care systems buy their drugs can also contribute to shortages. "Certainly purchasing strategies, such as tendering, which limit [the number of] suppliers, can contribute to shortages by making the supply chain more vulnerable," said Connell.

Bulk purchasing by large health care providers, even provinces, in pursuit of the lowest prices may lead to shortages, agrees Paul Grootendorst, an economist at the University of Toronto's school of pharmacy. Pushing down the price on a product with already thin margins can drive some suppliers out of the market. "When governments interfere to keep prices low, people don't bother to supply."

This has been especially evident in New Zealand, which has a tendering system and suffers from chronic shortages, said Grootendorst. "They have a heck of

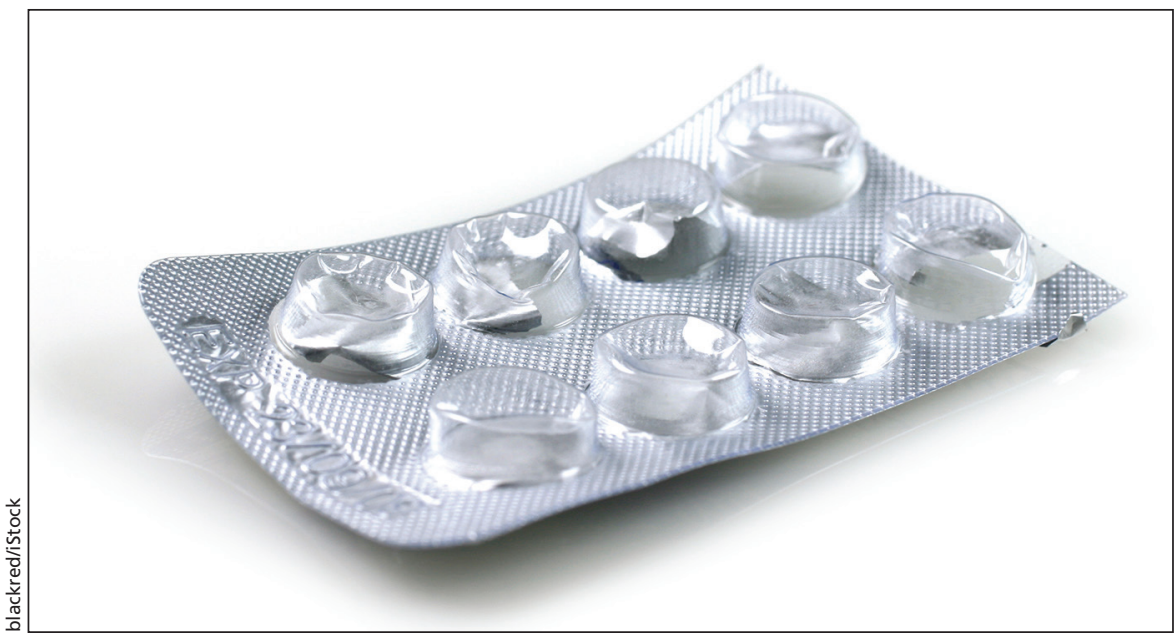

Experts say the problem of drug shortages boils down to economics.

a time keeping drugs in stock," he said, despite the fact that the tenders have supply assurances built in, with penalties for failures to supply.

In the US, there is another suspected culprit, the group purchasing organizations, or GPOs, that supply hospitals and health care providers with everything from intravenous poles to bedsheets, but whose biggest ticket items are drugs. Some have been accused of violating anti-trust rules by providing kickbacks to drug companies in exchange for the right to buy up their entire stock, effectively creating monopolies on certain drugs.

But above all, shortages are essentially an economic problem, said Grootendorst, and one that can be fixed fairly easily. "If you want to pay enough, the drug will get produced."

As the debate continues on the underlying causes, various players are trying at least to document or report shortages. Innovative Medicines Canada, the trade association for the brandname pharmaceutical industry, runs a voluntary online database where companies can post information about current shortages and estimates as to when the drugs will be available again.

Duffin says the way the database is structured is not particularly helpful, and most Canadian doctors and pharmacists use the FDA database, or one run by the University of Utah's School of Pharmacy.

In 2015, the federal government announced it would bring in rules for mandatory reporting of shortages. Dr. Supriya Sharma, a senior medical advisor at Health Canada, said regulations should be public this spring or summer. The department recently tendered for the website, which will replace the current industry-run site.

Since 2012, the department has brought together drug manufacturers, doctors and pharmacists to figure out how to deal with shortages. "When a shortage is imminent or in progress, we bring people together to coordinate an appropriate response," said Sharma.

For example, the current shortage of the antiseizure drug divalproex sodium was the result of manufacturing issues. In response, the department gathered pharmacists, patient groups, provinces and suppliers from around the world to determine the extent of the shortage and figure out where they could get new supplies. In the end, another company stepped in and increased their production by $600 \%$ to try to fill the gap though the drug can still be hard to find.

Whatever the causes, and eventual solutions, the drug shortage is posing a serious, tangible cost to patients right now, even if little is being done to record it, said Duffin. "There is nothing we are required to fill out when somebody dies; they die of a disease, they don't die of drug shortage," she said. But she has no doubt that the shortage of prochlorperazine had a major effect on her patient's life. "She died of cancer, eventually, this poor woman, and she suffered way more than she had to because she couldn't get that drug." Brian Owens, St. Stephen, NB

CMAJ 2016. DOI:10.1503/cmaj.109-5282 